\title{
The importance of seismic protection of strategic objectives, in the area of influence of useful rock quarries, in which blasting works are carried out
}

\author{
Bogdan Garaliu-Bușoi ${ }^{1 *}$, Attila Kovacs $^{1}$, Edward Gheorghiosu ${ }^{1}$, Cristian Rădeanu ${ }^{1}$, and \\ Olga Miclea $^{1}$ \\ ${ }^{1}$ National Institute for Research and Development in Mine Safety and Protection to Explosion - \\ INSEMEX Petrosani, Department of Safety of Explosion and Pyrotechnic Articles, G-ral V. Milea \\ Street 32-34, Petrosani, Romania.
}

\begin{abstract}
In this scientific article was studied the main methods for assessing the seismic effect generated during the blasting operations with explosives, from quarries on essential infrastructure elements, in the analyzed situation - railway tunnel and supporting pillars of the railway superstructure in the adjacent area of the quarry, regarding the most appropriate technique for estimating and assessing the seismic effect through the specificity of the evaluated parameter.

In order to be able to carry out an activity with as little impact as possible on the environment, the economic operator carrying out career blasting works must apply technical measures to ensure the protection of civil / industrial objectives in the area close to carrying out these works.

The establishment of measures leading to the maintenance of the stability and integrity of the objectives, as well as to the protection of the environment, is based on an artificial earthquake assessment process, which highlights the possible effects on the adjacent area.

The evaluation of the seismic effect can be done by monitoring some parameters that characterize the seismic waves produced by quarry blasting such as: frequency of oscillations, amplitude of movement, soil particles oscillations velocity, acceleration of oscillations, duration of their manifestation.
\end{abstract}

\section{Introduction}

Drilling technology with blasting holes drilling and explosive blasting has proven to be a very effective technology for medium, high and very high rocks strenght. However, poor control of technological parameters can produce effects that can affect the population in the nearest area in terms of noise levels, dust and the release of significant amounts of toxic gases into the atmosphere. A very important aspect is the generation of seismic waves that

\footnotetext{
${ }^{*}$ Corresponding author: bogdan.garaliu@insemex.ro
} 
propagate in the geological structure, even at significant distances, and that can influence the structures that need protection against this phenomenon $[1,2,3]$.

Seismic waves generated repeatedly when performing blasting works can lead to irreversible deformations and destruction of geological structures in the area adjacent to the quarry where civil or industrial constructions are carried out, or railway or road infrastructure works considered to be strategic objectives.

Railway and road tunnels are works whose expected lifespan is hundreds of years and their repair and consolidation activities are particularly difficult and expensive. In this regard, it is preferable that human activities, such as heavy traffic or other works, be carried out in a controlled and predictable manner. Thus, the blasting works for the exploitation of the useful rocks from the adjacent area must be carried out with the imposition of restrictions meant to diminish the seismic effects both at each blasting and the cumulative effect of their repetition.

The paper aims to present the activities carried out to monitor the seismic effects generated by quarry blasting works on essential infrastructure elements, in the analyzed situation - railway tunnel and railway superstructure pillars support in the adjacent quarry area.

In this sense, for the career studied, an assessment of the seismic effect generated by the blasting work is considered, based on engineering measurements and calculations for the assessment of seismicity, in various scenarios involving different places of blasting in the quarry, the total amount of explosive detonated on the delay step and monitoring the effects at the chosen points of importance in the field.

The level of seismicity is influenced by a number of factors that can be grouped into natural (intrinsic) and technological (anthropogenic) factors.

Of the most important natural factors we must mention [4, 5]:

- Topographic elements (distance from the front to the measuring point, position and spatial orientation of the front from the measuring point both horizontally and vertically).

- Geological specificity (nature and strength of rocks in the area, their consistency, the presence of faults or other tectonic accidents).

- The hydrogeological specificity, as the presence of groundwater, the level of the groundwater, helps to efficiently transmit seismic waves.

- The level of afforestation of the relief.

These natural factors must be considered as such and only through technological measures can the amplitude of the oscillations of the soil particles be controlled.

The technological factors to be taken into account refer to the technological parameters of the drilling and blasting work as well as the characteristics of the explosives used. Factors related to drilling holes are: diameter and length of holes, anticipation at the front, distance between rows and their number, distance between holes in the same row, orientation to the front profile, deepening.

The specific factors of the loads in the hole are: the type / types of explosive loaded, quantity per hole, mode of initiation (anterior, posterior or multipoint, length and quality of the sealing).

A determining factor in achieving a level of seismicity when blasting is the choice of delay steps, the order of the holes delays in rows and between adjacent rows. Setting the delays will allow you to set the maximum load on the various delay steps.

The initiation resources election will determine the amount of explosive blast once, so when using the ignition fuse network, all charges will detonate simultaneously, leading to a maximum amount of explosive charge and a significant seismic level. Electric caps allow the choice of a limited number of delays, which on fronts with a large number of holes, it is necessary to establish a number of holes that will be blast with the same delay. 
Non-electric initiation systems allow a much larger but still limiting number of delays steps to be achieved. At the same time, the length of the shock tube, in certain situations, for long holes, will not always allow the initiation close to the bottom of the hole. Electronic caps initiation systems eliminate the aforementioned shortcomings, as they can be programmed for individual delays on the hole, so the load on the delay step will be the load on the hole itself. However, the costs related to electronic caps are significantly higher than in other systems and currently in Romania the use of non-electric caps has become widespread in surface works, the costs being reasonable and an adequate level of security is ensured.

In the case of a proper initiation, a decomposition reaction takes place in an explosive, the rate of the reaction being determined by the type of substances that make up the explosive. The speed of propagation of the detonating wave in the mass of the explosive is $2000 \ldots 8000 \mathrm{~m} / \mathrm{s}$.

Based on the analysis, if necessary, the technological characteristics specific to the blasting should be reconsidered and the limit of the explosive limit for each scenario should be established.

\section{Methodology regarding the determination of the seismicity level in the area of influence of the quarries where blasting works are performed and the monitoring equipment used}

\subsection{Methodological considerations}

The explanation of the mechanism of rock crushing by blasting cannot be done without taking into account the mechanism of transmission of explosive energy in the rock and the state of tension in the massif $[6,7]$.

The transmitted pressure propagates through the rock in the form of an oscillating wave through which the shock energy is transmitted. Due to the distribution of energy on smaller and smaller surfaces, as well as the fact that the environment in which it propagates is not perfectly elastic, the intensity of the oscillations decreases rapidly, the wave damping.

Knowing how to transmit the shock wave in the massif, you can also study how to transmit energy from explosive to rock. It is known that the pressure in front of the shock wave far exceeds the value of the compressive strength of the most resistant rocks. As a result, in the immediate vicinity of the load, a rock crush occurs, the value of the pressure being reduced to values that no longer allow the further propagation of the wave in the form of a compression wave. However, due to the breaking of the rocks, irreversible transformations such as ruptures, cracks and fissures occur in the neighborhood. Next, the shock wave being almost completely damped, it propagates in the form of elastic oscillations, which are manifested by vibrations.

In conclusion we can mention that there are 3 areas of influence of the explosion (Figure 1) the crushing area, the cracking area and the area of elastic deformations. 


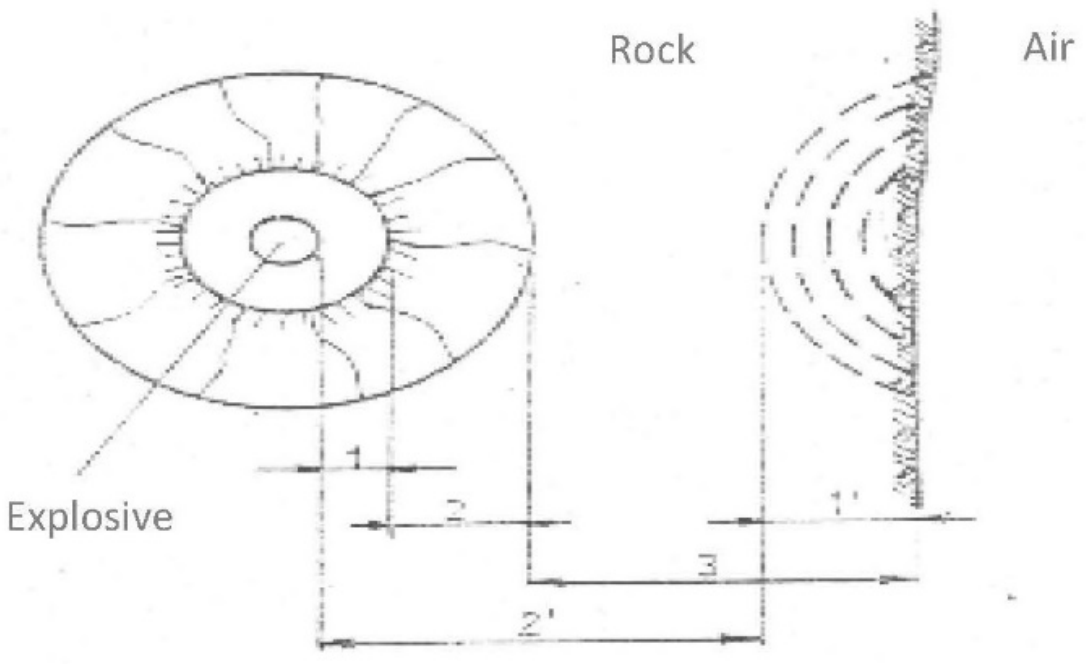

Fig. 1. Areas of the explosion influence.

Meeting planes of separation between different types of rocks in the massif, natural fissures, cracks and even crevices, the system of compression and traction waves is reflected, rising to new types of waves, creating a complex state of tension in the massif. As a result, the system of cracks existing in the massif or the one created by the incident waves, is further developed.

Elements sensitive to ground oscillations can be varied: civil and industrial constructions (residential buildings, administrative buildings, factories, halls, etc.) works of art (on the surface: bridges, towers, retaining walls, etc. or underground: tunnels, tanks, sewers, etc.). In certain situations, natural areas and especially steep slopes of hills and mountains are also affected.

The design of the parameters of a blast must take into account the danger caused by vibrations induced in the field, the main parameter that characterizes the seismic effect is the speed of particle oscillation.

The following methods are used to assess the seismic effect [8]:

a) relative energy method (ER)

$$
E R=\frac{a^{2}}{f^{2}}
$$

where:

a - maximum particle acceleration;

$$
\mathrm{a}=877,95 \mathrm{Q}^{3 / 4} \mathrm{r}^{2} \quad \mathrm{~g}\left(\mathrm{~m} / \mathrm{s}^{2}\right)
$$

$\mathrm{r}$ - distance from the blasting area

$\mathrm{Q}$ - the amount of explosive in tons.

b) the Zeller criterion, defined as the ratio:

$$
Z=\frac{a^{2}}{f}
$$

Based on the $\mathrm{Z}$ relation, the Zeller scale (Table 1) was drawn up, which differentiates 12 influence classes according to the value of $Z$. 
Table 1. Zeller scale.

\begin{tabular}{|c|c|}
\hline $\begin{array}{c}\text { Intensity factor, } Z \\
\left(\mathrm{~cm}^{2} / \mathbf{s}^{3}\right)\end{array}$ & Brief description of the earthquake \\
\hline$<2$ & Imperceptible \\
\hline 2 & Very easy \\
\hline 10 & Easy \\
\hline 50 & Measurable (small cracks) \\
\hline 250 & Pretty strong \\
\hline 1000 & Strong - below the danger zone \\
\hline 5000 & Very strong (severe cracks) \\
\hline 20000 & Destructive \\
\hline 100000 & Devastating \\
\hline 500000 & Shattering \\
\hline 2500000 & Calamitous \\
\hline 10000000 & Very catastrophic \\
\hline
\end{tabular}

c) vibration intensity method

$$
\mathrm{S}=10 \log (10 \mathrm{Z})=10(1+\log Z)
$$

Depending on which the hazard scale was drawn up (Table 2) with 5 classes of influence.

Table 2. Hazard scale (vibration).

\begin{tabular}{|c|c|c|}
\hline $\begin{array}{c}\text { Vibration intensity, } \\
\text { S }\end{array}$ & Vibration classification & The effect on construction \\
\hline $10-20$ & Light & There is no danger \\
\hline $20-30$ & Medium & There is no danger \\
\hline $30-40$ & Strong & $\begin{array}{c}\text { Slight damage } \\
\text { (cracking of the walls) }\end{array}$ \\
\hline $40-50$ & Severe & $\begin{array}{c}\text { Cracking of retaining } \\
\text { walls }\end{array}$ \\
\hline $50-60$ & Very severe & Destruction of buildings \\
\hline
\end{tabular}

d) particle velocity method:

The dynamic shock wave generated by the explosion is transmitted en masse in the form of a spherical seismic wave, a wave that propagates at different speeds depending on the nature and compactness of the ground generating its vibrations, the amount and type of explosive and subjecting the environment to different types of stress. .

The transmission of the dynamic shock wave in the ground, determines the decomposition of the speed into 3 components (Figure 2). 


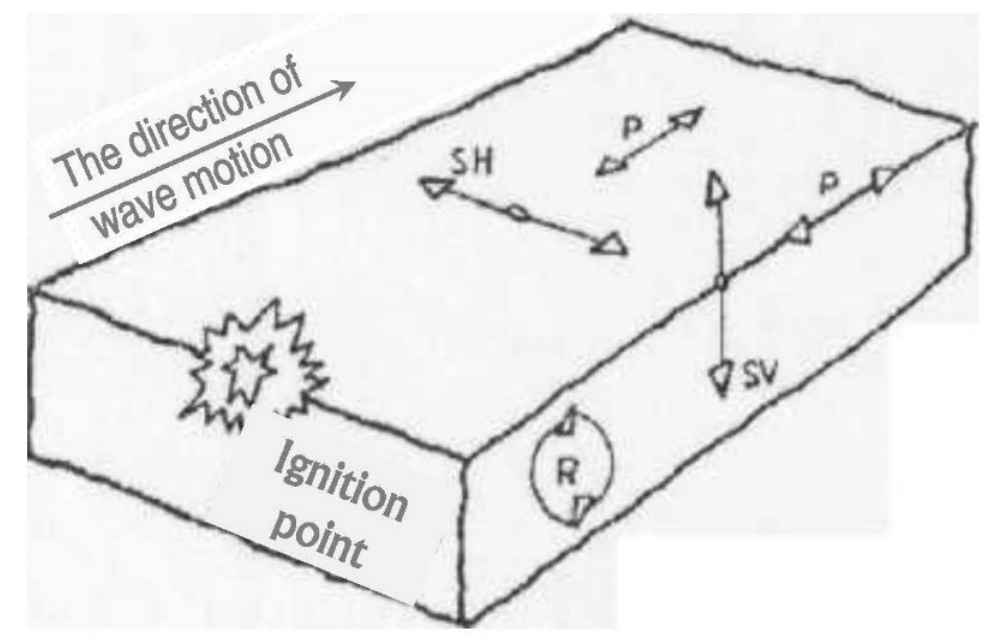

Fig. 2. Seismic waves generated by an explosion in the ground.

where:

P - compression wave; SH - horizontal shear wave; SV - vertical shear wave; R Rayleigh wave.

- the radial component $\mathrm{P}$ - compression wave, also called primary wave, has the highest speed and reaches the recorders first, causing a thinning of the environment. Soil particles under the incidence of this wave move in the direction of propagation, and the density of the ground changes when the wave passes. The speed of $\mathrm{P}$ waves can exceed $5000 \mathrm{~m} / \mathrm{s}$;

- $\quad$ horizontal $(\mathrm{SH})$ and vertical (SV) components called secondary waves, propagated perpendicular to the direction of radial wave propagation develop shear stresses as an effect of compressing the environment in the primary wave advance front. The secondary wave propagation speed is $2 / 3$ of the primary wave value.

When the primary and secondary waves meet a discontinuity surface - that is, the surface of the ground, they reflect and generate surface waves - Rayleigh waves.

The maximum vertical displacement of a particle due to surface waves $\mathrm{R}$ (Reyleigh waves) is given by the expression:

$$
\mu_{\mathrm{z}}=1900\left(\mathrm{r}_{\mathrm{o}} / \mathrm{c}_{\mathrm{p}}\right) \alpha\left(\mathrm{Q} / \mathrm{r}_{0}\right) \mathrm{f}(\bar{r}) \quad(\mathrm{mm})
$$

where:

$r_{o}$ - is the distance from the point of explosion at which the waves become quasi-elastic and which can be calculated with the relation:

$$
\mathrm{r}_{0}=\mathrm{k}_{0} \sqrt[3]{Q}(\mathrm{~m})
$$

where:

$\mathrm{k}_{0}=4,5 ; 3 ; 2,5 ; 6-8$ respectively for granite, shale, loess sandy clay and loam.

The function $\alpha\left(\mathrm{Q} / \mathrm{r}_{0}\right)$ expresses the effect of the sealing hole depth of the blast and has a maximum value of 1.5 .

The function $\mathrm{f}(\bar{r})$ has the form:

$$
\mathrm{f}(\bar{r})=(\bar{r})^{-0,5} \cdot \mathrm{e}^{-1,75(\bar{r}) 0,2}
$$

where: 


$$
\bar{r}=\frac{r}{\sqrt[3]{Q}}\left[\mathrm{~m} / \mathrm{kg}^{1 / 3}\right]
$$

The calculation of $\mathrm{f}(\bar{r})$ depending on $\bar{r}$ it is tabulated according to the table 3:

Table 3. Dependence between $\mathrm{f}(\bar{r})$ an $\bar{r}$.

\begin{tabular}{|c|c|c|c|c|c|c|}
\hline$\overline{\boldsymbol{r}}$ & $\mathbf{1}$ & $\mathbf{2}$ & $\mathbf{5}$ & $\mathbf{1 0}$ & $\mathbf{2 0}$ & $\mathbf{5 0}$ \\
\hline $\mathrm{f}(\bar{r})$ & $17,4.10^{-2}$ & $9,5.10^{-2}$ & $4.10^{-2}$ & $2.10^{-2}$ & $9,3.10^{-3}$ & $3,8.10^{-3}$ \\
\hline $\bar{r}$ & 100 & 200 & 500 & 1000 & 2000 & 5000 \\
\hline $\mathrm{f}(\bar{r})$ & $1,23.10^{-3}$ & $4,58.10^{-4}$ & $1,03.10^{-4}$ & $3.10^{-5}$ & $7,5.10^{-6}$ & $3,2.10^{-6}$ \\
\hline
\end{tabular}

The maximum horizontal displacement $U_{H}$ in the $R$ waves can be determined by knowing the ratio $U_{H} / U_{Z}$, which has the values: $0.6 \div 1.1$ for granite; $1 \div 2.2$ for clay; $1.4 \div$ 1.8 for loess.

The maximum velocity of the particle in the vertical plane, for $\mathrm{R}$ waves, can be calculated with the relation:

$$
\bar{r}=\frac{1,19.10^{4} \cdot r_{0} \phi\left(Q / r_{0}\right) \cdot f(\bar{r})}{C_{p \cdot K_{T}} \sqrt[6]{ } Q \cdot(\bar{r})^{n}} . \quad[\mathrm{mm} / \mathrm{s}]
$$

The maximum speed in the horizontal plane is:

$$
\mathrm{v}_{\mathrm{H}}=\mathrm{v}_{\mathrm{z}} \mathrm{U}_{\mathrm{H}} / \mathrm{U}_{\mathrm{z}}
$$

As the distance from the blasting site increases, surface waves attenuate much more slowly than $\mathrm{P}$ and $\mathrm{S}$ waves (volume waves), and at a distance of more than $100 \mathrm{~m}$ their influence is predominant, while the blasting process takes several milliseconds, the vibration induced by detonations persists for tens of seconds or even a few seconds, in the vicinity of the place of detonation the ground particles are at a certain time and for a certain period of time subjected to complex vibrational movements, a movement that has an effect on objectives in the area.

The recording of the waves generated by the blasting on seismographs determines the identification of the variation in time of the 3 components of the ground vibration speed.

\subsection{Equipment needed to monitor the seismic effect generated by the blasting works}

Specialized companies have developed the infrastructure for monitoring the seismic effect from quarry blasting works and provide a wide range of increasingly complex equipment that can measure the parameters that characterize seismic waves $[9,10]$.

Well-known manufacturers in the field are INSTANTEL in Canada and NOMIS in the USA.

Thus, we meet NOMIS type seismographs (Figure 3) and INSTANTEL type (Figure 4) which are very complex devices and which can measure and record the parameters that characterize seismic waves. 


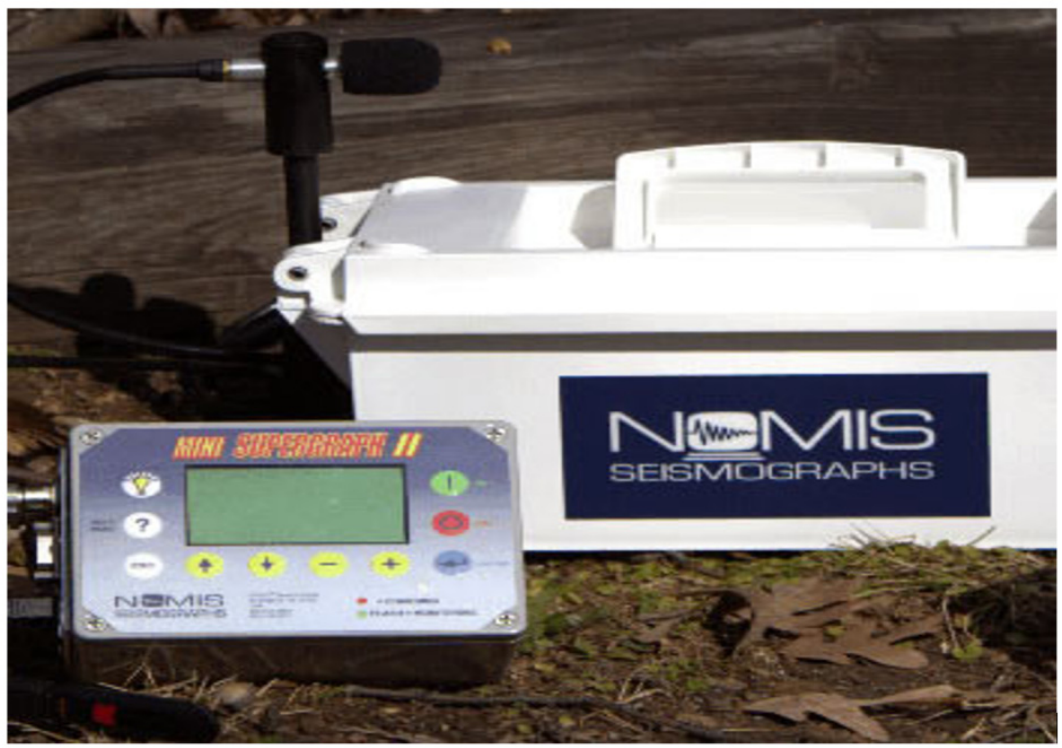

Fig. 3. NOMIS seismographs.

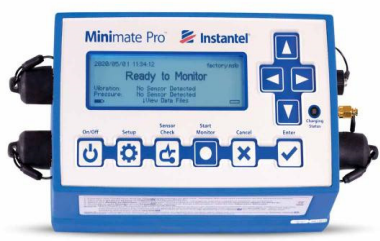

Fig. 4. INSTANTEL seismographs.

The measuring assembly consists of the data storage and recording unit to which the sensors (transducers) that are particularly sensitive to ground vibrations are coupled, produced on 3 components: vertical, transverse and longitudinal.

The transducers are provided at the top with an arrow that must be oriented in the direction of the event so that the sensor of the geophone inside the transducer remains positioned in its natural axes. Improper placement can allow the transducer to move independently on the measuring surface, often resulting in sometimes large distortions of the measurement results. The method of fixing depends on the type of existing surface, the transducer having to be fixed to the surface by a fixed clamp, thus ensuring an accuracy of the measurement results.

A method applicable in the case of low intensity vibrations, uses a sandbag that is placed over the transducer.

A new generation of geophones are SmartGeo from Instantel (Figure 5) with automatic orientation and adjustment of settings for correct reading of vertical, transverse and longitudinal vibrations, this allows the transducer to be placed in any orientation, it will adjust and correct automatically for the appropriate level and position, either horizontally or vertically. In this situation there is no need for 2 separate geophones for horizontal 
mounting and vertical mounting. SmartGeo can be installed upside down and will make accurate recordings, although this is not recommended.

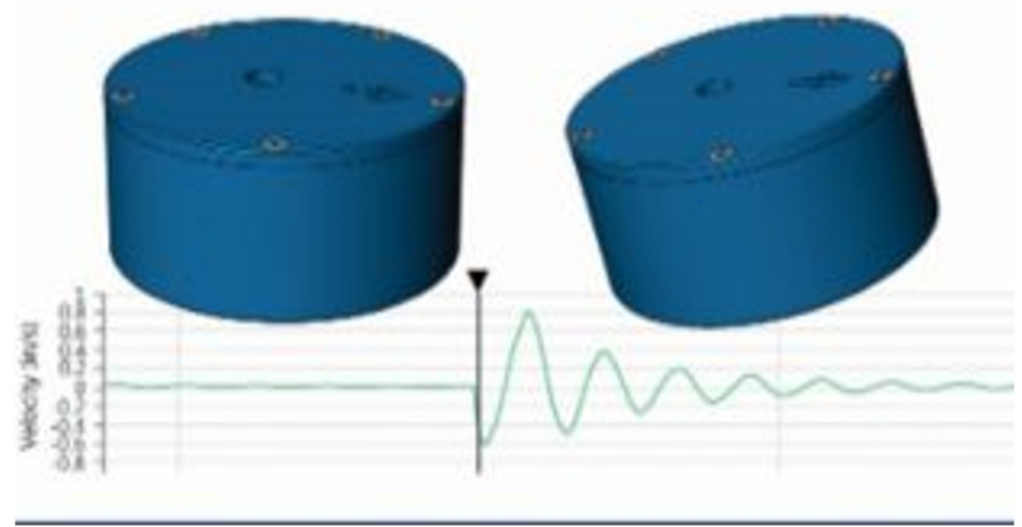

Fig. 5. Instantel SmartGeo Geophone.

\section{Case study on the preliminary assessment of the effects of quarry blasting works on the Curtici - Simeria railway line, in order to protect the superstructure and tunnel works}

The quarry that is the object of the study is located in Arad county, near Bata locality (figure 6), where it is extracted by blasting works, basalt, as a useful rock. Due to the nature of the works, the quarry can influence other objectives in the area such as the European Road E68, local roads in the area, and more recently the problem of studying the seismic protection of the Curtici - Simeria railway constructions, work that is underway [11].

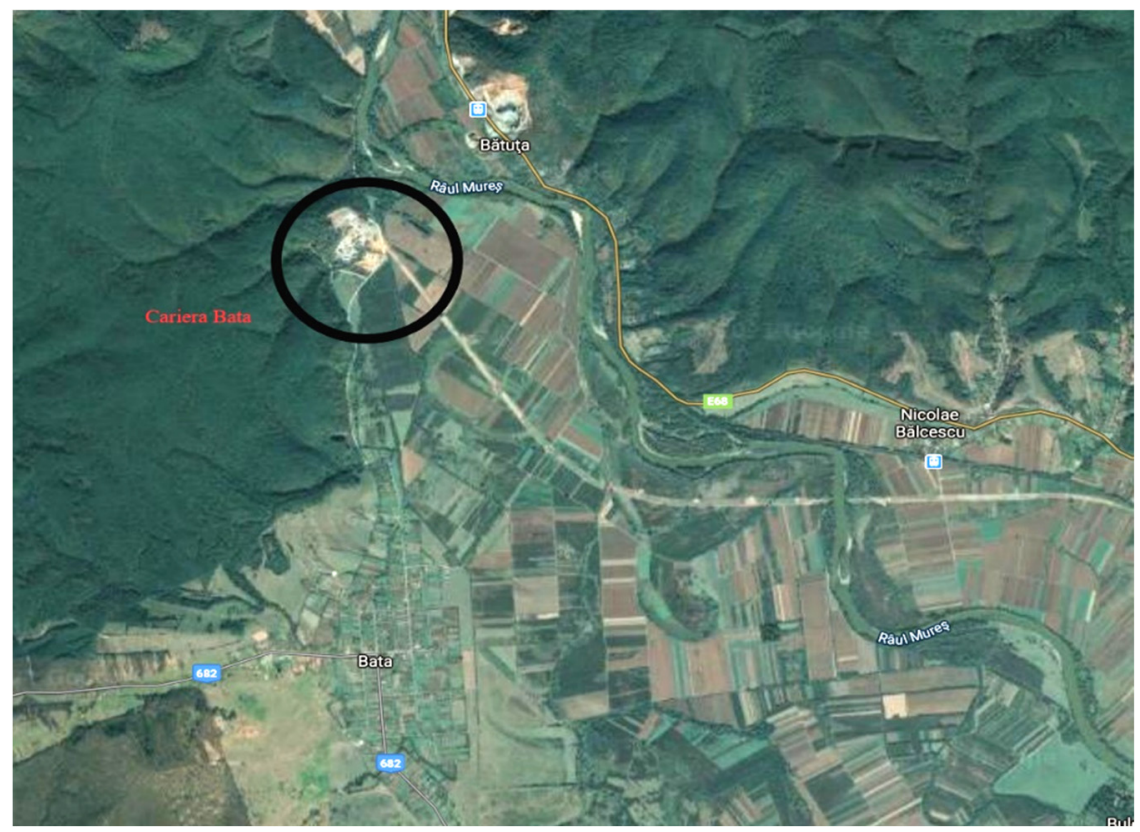

Fig. 6. Bata quarry view. 
The work for the construction of the new railway line, in the Bata area, consists of the location of some pillars for the superstructure and a tunnel west of the area of interest. Given that these works are expected to have a very long lifespan, their protection requires an assessment and monitoring that involves both geotechnical studies and seismic assessment.

INSEMEX specialists provide technical assistance in assessing the seismic effects generated by blasting works, implementing a program of systematic seismic measurements, in the points of interest in the quarry area, such as: the tunnel, respectively the pillars supporting the railway superstructure.

The area in question is an aquifer, due to water infiltration from the slopes, as well as the presence of the Mureș River in the vicinity. It should be noted that the seismic effect is much more difficult to softens in areas with aquifers or where there is water, and this must be taken into account for the correct assessment of the seismic effect.

The quarry, being developed, through the work fronts, on the existing steps, which can be reconfigured later, will lead to the need to re-evaluate the seismic effect generated by the blasting works. It should be recalled that with the commissioning of the new railway, the seismic effect resulting from blasting will be combined with the effect generated by the movement of train sets and road transport of excavated rock.

The drilling - blasting operation is performed with vertical holes, located in a chessboard blasting network, using explosive type Riogel XE, Riogel HE and Anfodet initiated with a Detinel type system, non-electric.

In this phase, during June 2020, preliminary measurements were performed which consisted of placing several NOMIS and INSTANTEL seismographs near the superstructure pillars, at the entry of the railway tunnel under construction, respectively on the access road from Bata commune.

The result of the measurements on the speed of oscillations of the environmental particles is presented in Table 4.

Table 4. Bata quarry measurements.

\begin{tabular}{|c|c|c|c|c|}
\hline No. & Blasting & Measurement locations & Device series & $\begin{array}{c}\text { The speed of } \\
\text { oscillations of } \\
\text { environmental particles } \\
\mathrm{W}[\mathrm{mm} / \mathrm{s}]\end{array}$ \\
\hline 0. & 1. & 2. & 3. & 4. \\
\hline 1 & \multirow{7}{*}{ I 1} & L1 - Railway concrete pillar & MP13953 & 11,684 \\
\hline 2 & & L2 - Access road & 3140 & 24,130 \\
\hline 3 & & L3 - Railway concrete pillar & 10702 & 12,700 \\
\hline 4 & & L4 - Tunnel entrance & 10692 & 157,353 \\
\hline 5 & & L5 - Tunnel entrance & 10691 & 74,295 \\
\hline 6 & & L6 - Access road & BE19772 & 148,209 \\
\hline 7 & & L7 - Access road & MP13644 & 2.540 \\
\hline
\end{tabular}

These results show that the seismic level for the blast with the quantities of explosive used, did not generate a dangerous seismic level, but it is argued the need to continue measurements at other blasts, especially to increase the total loads and the load on the delay step, respectively blast hole.

The frequency of blasting in the Bata quarry, belonging to SC DIABAS BATA SRL, is not particularly high, but requires a systematic assessment in order to establish limit quantities of explosives that do not produce seismic effects that could harm railway construction. 


\section{Conclusions and proposals}

Blasting works, whether surface or underground, concerns useful mineral substances or controlled demolition, are generating local earthquakes that can affect civil and industrial construction, or the stability of rocks in the area of the exploitation area.

The level of acceptability for earthquakes triggered by blasting works is correlated with the importance and vulnerability of the objectives to be protected.

INSEMEX's concerns concern these measurements and evaluations for all the works mentioned, stating that each case study has its own particularity, and neither the measurements nor the evaluation itself can be extrapolated to other similar works.

Following these measurement and evaluation actions, INSEMEX will be able to issue a Certificate attesting that the level of seismicity is acceptable for the given conditions.

\section{References}

1. Gheorghiosu E., Găman G.A., Ghicioi E., Kovacs A., Vasilescu D.G., Guide for evaluating the seismic effect generated by quarry blasting works, ISBN 978-606-8761-04-6 (2018)

2. Gheorghiosu E., Rus D.C., Ciocoiu C.D., Lupu C., Good practice guide for the storage, transport and use of explosives (INCD Insemex, Petrosani, 2008)

3. STAS 3684-71 - Seismic intensity scale

4. Core study with the methods used at national level for monitoring, forecasting and evaluating the intensity of seismic waves generated by quarry blasting works, PN 16430221 (2016-2021)

5. Fodor, D., Quarry exploitation of deposits of mineral substances and useful rocks (Corvin publishing house, Deva, 2008)

6. Calvin, J. K., Surface blast design for Romanian operations

7. Gheorghiosu, E.J., Current state of design and application mode of felling techniques, by means of blasting work used in daylight operations, Doctoral Scientific Report no. 1, Petrosani

8. Gheorghiosu, E.J., Research on the optimization of geometric and quantitative parameters of blasting techniques, Doctoral Scientific Report no. 2, Petrosani

9. Minimate Pro-Product manual.

10. Nomis SuperGraphics II - User Guide.

11. Gheorghiosu, E.J., Results obtained regarding the reduction of the seismic effect generated by the blasting works, Doctoral Scientific Report no. 3, Petrosani 